\title{
Right ventricular failure after cardiac surgery: Why can't right ventricular assist device support fix the problem?
}

\author{
Francis D. Pagani, MD, PhD
}

\author{
From the Department of Cardiac Surgery, University of Michigan, Ann Arbor, Mich. \\ Disclosures: Author has nothing to disclose with regard to commercial support. \\ Received for publication April 28, 2018; revisions received April 28, 2018; accepted for publication April 30, \\ 2018; available ahead of print June 14, 2018. \\ Address for reprints: Francis D. Pagani, MD, PhD, 5161 Cardiovascular Center, University of Michigan, 1500 \\ East Medical Center Drive, Ann Arbor, MI 48109 (E-mail: fpagani@umich.edu). \\ J Thorac Cardiovasc Surg 2018;156:1881-2 \\ $0022-5223 / \$ 36.00$ \\ Copyright (C) 2018 by The American Association for Thoracic Surgery \\ https://doi.org/10.1016/j.jtcvs.2018.04.118
}

Right ventricular (RV) failure requiring mechanical circulatory support after cardiac surgery is a formidable problem. Poor outcomes and the lack of a similar array of device options available for left ventricular failure have often discouraged surgeons from appropriately applying right ventricular assist device (RVAD) therapy in a timely fashion. In this issue of the Journal, Bhama and colleagues, ${ }^{1}$ from the University of Pittsburgh, report on a single-center, retrospective, observational experience of 80 patients receiving RVAD support for RV failure after cardiac surgical procedures. In this study, RVAD support was performed in the setting of RV failure after cardiac transplantation, durable left ventricle assist device implantation, and postcardiotomy failure after other types of cardiac surgical procedures. Outcomes were markedly worse in those patients with postcardiotomy failure with lower survival and rates of weaning from RVAD support compared with patients with RV failure in the setting of cardiac transplant or durable LVAD implant. Of note, survival was particularly worse in patients receiving delayed versus immediate institution of RVAD support. Last, the investigators observed that outcomes with RVAD support appeared similar across eras with no apparent improvement over time.

This study by Bhama and colleagues ${ }^{1}$ has made a number of pertinent observations that highlight important issues in the field. Mechanical circulatory support device options specific for RV applications that can be easily applied at the time of surgery allowing for patient mobility in the intensive care unit for variable periods of time (days to weeks) and permitting removal without repeat operative intervention are lacking. Newer device options with demonstrated efficacy and specific to the RV are available but do not necessarily encompass all the ideal traits noted. ${ }^{2}$ Despite the well-known effects of delayed treatment of cardiogenic shock, the institution of RVAD support is often delayed because surgeons frequently underestimate the degree of severity of the

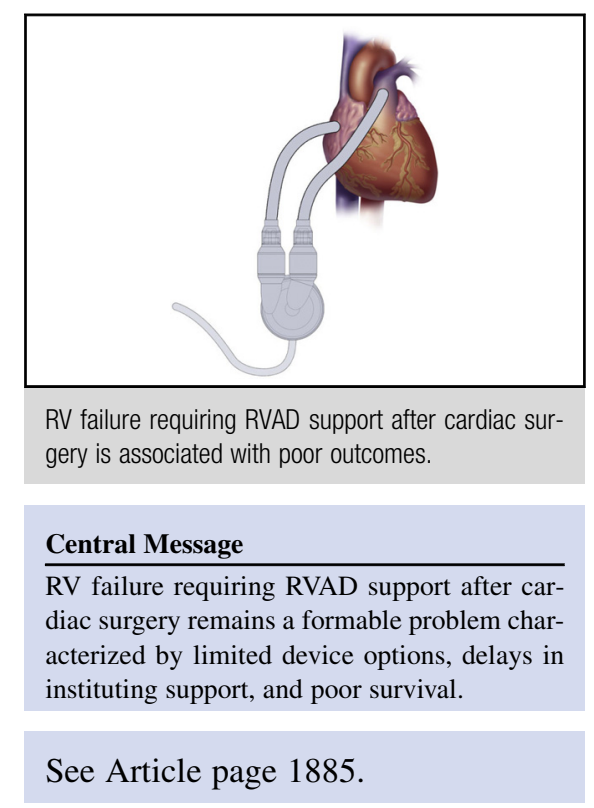

RV failure, believe that medical therapy can be effective, or are discouraged from proceeding with RVAD support because of the lack of suitable mechanical circulatory support options. ${ }^{3}$ Last, despite the increasing awareness of the impact of RV failure on surgical outcomes, the study by Bhama and colleagues ${ }^{1}$ did not demonstrate improvement in outcomes over time, supporting previous observations from the Interagency Registry of Mechanically Assisted Circulatory Support. ${ }^{4}$ However, this last observation may have been a reflection of the limitations of statistical analyses in a small patient cohort because the trend in survival for the most recent era in the study by Bhama and colleagues ${ }^{1}$ did demonstrate evidence of clinical relevance.

The study by Bhama and colleagues ${ }^{1}$ is continuing evidence of the importance of RV failure after cardiac surgery and the limitations in our continued approach to the problem. Thoughtful solutions rely on the ability to develop new technology and of surgeons to apply the technology in an appropriate and timely fashion.

\section{References}

1. Bhama JK, Bansal U, Winger DG, Teuteberg JJ, Bermudez C, Kormos RL, et al Clinical experience with temporary right ventricular mechanical circulatory support. J Thorac Cardiovasc Surg. 2018;156:1885-91. 
2. Kapur NK, Paruchuri V, Jagannathan A, Steinberg D, Chakrabarti AK, Pinto D, et al. Mechanical circulatory support for right ventricular failure. JACC Heart Fail. 2013;1:127-34.

3. Fitzpatrick JR III, Frederick JR, Hiesinger W, Hsu VM, McCormick RC, Kozin ED, et al. Early planned institution of biventricular mechanical circulatory support results in improved outcomes compared with delayed conversion of a left ventricular assist device to a biventricular assist device. J Thorac Cardiovasc Surg. 2009;137:971-7.

4. Kirklin JK, Pagani FD, Kormos RL, Stevenson LW, Blume ED, Myers SL, et al. Eighth annual INTERMACS report: Special focus on framing the impact of adverse events. J Heart Lung Transplant. 2017; 36:1080-6. 